\title{
Kršćani, pogani i neoplatonisti - problem odnosa u kasnoj antici
}

\author{
Tomislav Čanković*
}

\begin{abstract}
Sažetak
Ovaj rad donosi sažeti prikaz kasnoantičkog odnosa (i njegovih karakteristika) između kršćanstva i neoplatonističke filozofije te položaja poganstva u kasnoj antici. Nakon terminološkog razjašnjenja, tekst na temelju radova i ideja izabranih analitičara predstavlja razlike u stavovima neoplatonističkih filozofa prema kršćanstvu i u stavovima kršćanskih autora prema neoplatonizmu i filozofiji općenito, te zanimljiv slučaj Sinezija iz Cirene, neoplatonističkog biskupa.
\end{abstract}

Ključne riječi: kršćanstvo, neoplatonizam, poganstvo, Sinezije iz Cirene

\section{Uvod}

Kada bi se zadjenuo razgovor o kasnoantičkom odnosu kršćana i njihovih religijsko-filozofskih takmaca, netko bi nedovoljno upućen mogao početi tendenciozno vikati: „Hipatija, Hipatija!“, osobito pod dojmom filma Agora (2009.), imajući pritom na umu nasilnu smrt aleksandrijske filozofkinje Hipatije 415. godine. Ta se „poganska mučenica“ uzima kao simbol borbe s početka 5. stoljeća između poganstva na izdahu i trijumfirajućeg kršćanstva (Marrou, 1970, 126). Pa ipak, sav potencijal te simbolike manifestira se induktivno, kao gromoglasan i markantan, ali i prevarantski vrh sante leda koji skriva kompleksniju sliku kasnoantičkog odnosa kršćana i njihovih „drugih“.

Slika je višeslojna, unatoč učestalim pokušajima dihotomijske simplifikacije. Odnos se može prikazati strukturom koja sadržava više hijerarhijski postavljenih razina. Već opisana dihotomija je prva, ali njezina nepreciznost ju čini neadekvatnim i manjkavim rješenjem, upravo jer uspostavlja kategorije koje su preširoke da bi bile korisne, a i sama terminologija ostaje problem kojem se nužno treba posvetiti. Druga razina bila bi narav odnosa, svediva na pitanje suživota ili sukoba, a treća razina obuhvaćala bi njihove podtipove. Suživot tako skriva mogućnosti miroljubivosti, tolerancije, uzajamnog poštovanja ili kakve druge idilične imenice, ili pak jedva prikrivenu hladnoću odnosa sa sretnim nedostatkom

* Tomislav Čanković. Adresa: Mramorni prilaz 34, 10040 Zagreb, Hrvatska. E-pošta: tcankoviczg@gmail.com 
nasilnog elementa. Sukob opet može prizivati fizičko, krvavo nasilje koje evocira simbolika Hipatije (i koje je tu zanemareno) ili suptilniju formu verbalnog, tekstualnog „nasilja“ koje tu uživa veću pozornost.

Dakle, terminologija je središnji problem — ona stvara iluziju jasnoće i definiranosti, skrivajući pritom lako propustive semantičke zamke. Pa ipak, odnos implicira barem dvije instance, a netko mora činiti „druge“. Najčešće se u popularnom diskursu javljaju pogani, čije terminološko preživljavanje u historiografiji može biti začudna pojava, ali pitanje se vraća: O kome je zapravo riječ? Taj nesretni naziv, obično negativnih konotacija, nosi teret generalizacije jer pretpostavlja teško održiv koncept nekakve formirane religije ili generalnog jedinstva nekršćanskih (ili pretkršćanskih) vjerovanja (Cameron, 2011, 25-32). Pogani su konstrukt vanjskog promatrača temeljen na dihotomiji (Mi-Oni) koja pripada diskursu kršćanskog kulturnog kruga sa svrhom formacije vlastitog identiteta u odnosu na ne-kršćanske Rimljane, u kontekstu prijelaza kršćanstva s margine u centar rimskog društva (Jürgasch, 2016, 124-125). Pojednostavljeno, iako se javljaju u prijevodu Novog zavjeta Bonaventure Dude — »kad molite, ne blebećite kao pogani« (Mt 6:7) - pogani su nebiblijski termin, na mjestu kojih u originalu stoji ethnikoi, preuzet iz latinskog vokabulara (paganus) u kojem je u osnovi označavao seljaka, no koji je u promijenjenim okolnostima kršćanima poslužio za popunjavanje terminološke praznine, odnosno za kreaciju ne-kršćanskog antipoda vlastitomu identitetu. ${ }^{1}$ Praktično govoreći, pogani su umjetna tvorevina čija je fiktivna egzistencija bila omogućena upravo stvaranjem novog (i za znanstvene potrebe nedovoljno preciznog) značenja pridodanog postojećemu terminu, čime su kršćani imenovali svoje „druge“ i ujedno učvrstili svoj zajednički identitet (O’Donnell, 2015, 159-162).

Neoplatonizam je na sličnim, labavim temeljima, ali je mnogo mlađi od pogana - moderni je konstrukt koji obuhvaća kasnoantička pluralna nastojanja sintetiziranja dotadašnje intelektualne baštine (uz neke iznimke), a ne monolitnu filozofsku školu (Moore, s.a.). Pritom oči bode laskavi, ali diskutabilni prefiks — ta je novost u odnosu na neki stariji platonizam upitna, a i sam naziv je kao identifikacijska oznaka nepoznanica, kako kasnoantičkim filozofima, tako i potencijalnim drugim uočavateljima koji jednostavno barataju pojmom platonizma (Wildberg, 2016). Opet, dakle, imamo svojevrsni vanjski konstrukt, nastao stoljećima nakon uočene pojave, te kategoriju koja, jednako kao poganstvo (s kojom je ponekad u krajnje pojednostavljenom sinonimnom odnosu), ne posjeduje autoidentifikacijsku funkciju. Ipak, u osuđenosti na baratanje nepreciznim nazivima, neoplatonizam barem obuhvaća uži krug ljudi i po kronološkom konsenzusu odgovara naslovnomu razdoblju, pa je koliko-toliko korisniji.

Kršćani su kao naziv u boljem položaju jer je, za razliku od pogana i neoplatonizma, riječ o eksplicitnoj autoidentifikacijskoj oznaci koja se javlja već u

1 Pojmu pogana, koji je zapadne provenijencije, prethodili su grčki nazivi jednako fleksibilnog značenja, poput spomenutog ethnikoi i Hellenes. O kasnoantičkoj terminologiji kojom su se služili rani kršćani, silnim značenjima koja su korišteni nazivi mogli poprimiti te uopće problematici iste, vidi iznimno poučno poglavlje The Perception of Paganism u: Jones, 2014, 1-8. 
novozavjetnim tekstovima (Dj 11:26, Dj 26:28) i kod apostolskih otaca (Ignacije Antiohijski, 2010, 66-67; III.2). Osim toga, postoje i nedvojbeno uočljivi napori usmjereni k formiranju unificiranog kršćanskog identiteta, odnosno ortodoksnog sustava vrijednosti (Jenkins, 2001, 115-116). No, što se prakse tiče, bolje bi bilo govoriti o kršćanskim identitetima² (Jürgasch, 2016, 122-123). Plural upućuje na primjetni pluralizam mišljenja: između ostalog, odnosi prema filozofiji se razlikuju, a i kod samih pojedinaca javljale su se oprečne ideje. Nema li tako sv. Augustin u različitim razdobljima različita stajališta o opravdanosti nasilja (Medved i Šiljeg, 2011, 428-430)? Pa ipak, ta tri naslovna naziva, kojima treba oprezno pristupiti, s većom suzdržanošću pri korištenju naziva pogani (koji za trenutačne potrebe neka budu ne-kršćani), čine sudionike u kasnoantičkom odnosu, čiju kompleksnu narav tek treba rasvijetliti, imajući na umu prije svega ograničen broj obrazovanih ljudi unutar kojeg se tekstualno „nasilje“ odvija. Stoga, kako izgleda kasnoantički međuodnos kršćana i neoplatonista, kršćana i pogana te neoplatonista i pogana? ${ }^{3}$

\section{O neoplatonizmu}

Zanemarivši nepreciznost, neoplatonizmom se smatra dominantna filozofska škola u kasnoj antici, za čijeg se osnivača obično uzima Plotina (204/5.-270.), Platonovog tumača i apologeta (Gerson, 2003), s Porfirijem, Jamblihom i Proklom kao nekim od kasnijih istaknutijih imena. Iako kritički nastrojeni neoplatonisti mogu namamiti nekoga u simplificirani dihotomijski okvir, neoplatonizam je »nezavisna filozofija koja nije a priori ni za ni protiv kršćanstva; istovremeno se pokazao kao prijatelj i kao neprijatelj« (Marrou, 1970, 145) u prevrtljivom odnosu koji je nekim kršćanskim autorima pružio vrlo korisno iskustvo.

Kršćansko-neoplatonistička polemika ostavila je primjetan tekstualni trag, a neobičnost te karakteristike očituje se u bliskosti rečenih filozofskih sustava — sam Augustin kaže da se među različitim filozofijama platonizam (!) najviše približio kršćanstvu (Aurelije Augustin, 1995, 562-563; 8.9). I prije Plotina platonizam je postao vrlo raširena misao koja je trpjela brojne interpretacije i transformacije, imajući pritom dalekosežan utjecaj. Čak je i logos Lukina evanđelja u stanovitom smislu platonistički (Moore, s.a.). Također, platonizam je bio konkurent mladomu kršćanstvu zbog henoteističkih tendencija kojima je počeo naginjati. Riječ je o ideji koja pretpostavlja vrhovno božanstvo, arhitekta i gospodara svega, ali koja ne isključuje druge, niže i podređene bogove. Henoteistički

2 Problematika kršćanskih identiteta kompleksna je i zahtijeva poseban rad. Srećom, tu je članak Which Early Christianity?, u kojem Karen King nudi pregled diskurzivnih razlika u dotadašnjim radovima na tu temu, ali i sugeriranu metodologiju kojom se nastoji skrenuti pozornost s esencijalističke kategorizacije kršćanskih identiteta na načine njihove proizvodnje, fokusirajući se upravo na razlike kao njezin ključan faktor (King, 2008).

3 Literatura o tim odnosima, posebice u novije vrijeme, postala je toliko brojna da se čini obeshrabrujućim uopće nastojati ju prezentirati. Stoga, u nedostatku prostora koji bi to pokrio i strahujući od nepreglednosti takvog pregleda, upućujem na: Sághy i Schoolman, 2017. 
bog stoga nije jedini, što je bitno obilježje koje mu nedostaje u odnosu na kršćanskoga, ali koje nije spriječilo spremnost nekih kršćanskih autora da priznaju stanovitu moć tim nižim bogovima, no kojima su u skladu sa svojim vjerovanjem oduzeli tu titulu i pripisali im ime zluradih i zlonamjernih demona (Moreschini, 2009, 30-31; Jones, 2014, 2 i 4). To se, između ostalog, pokazalo dovoljnim da antički autori uoče sličnosti među dvama sustavima, toliko da su neki neoplatonisti napadali kršćansko učenje kao krivotvoren ili pogrešno protumačen platonizam (Moreschini, 2009, 91). S druge su strane neki kršćanski pisci, skloni i bliski platonizmu, također pisali protiv neoplatonističkih autora u čijim su djelima vidjeli nepoželjan otklon od originalnih misli. Tako su Porfirije i njegovi simpatizeri kasnije smetali i Augustinu, koji se njima pozabavio ponajviše u 10. knjizi djela De civitate Dei, pri čemu je uspostavio zanimljivu distinkciju između Plotina, kojeg poštuje kao najboljeg Platonovog tumača (Aurelije Augustin, 1995, 642-643; 9.10), te njegova učenika Porfirija, kojeg između ostalog kritizira da je iskrivio i pogrešno odbacio neka Platonova (i Plotinova) učenja (Aurelije Augustin, 1995, 756-759; 10.30). Povremeno je isticanje tih podudarnosti među sustavima imalo različite svrhe: manje sintetske, više diskreditacijske. Unatoč bliskosti, ostale su nepomirljive i teško savladive prepreke - između ostalog, utjelovljenje logosa, uskrsnuće tijela, kozmogonija, soteriologija, pitanje božanske naravi (Simmons, 2002, 861 $)^{4}$ — koje su uzrokovale žustro prepucavanje.

Posegne li se za simbolikom antičkih gradova pri govoru o odnosima kršćana i neoplatonista, nasuprot Jeruzalemu stoje Atena i Aleksandrija, odnosno njihove filozofske škole, koje su, unatoč povezanosti tradicijom i studentskim razmjenama, razvile primjetljivo suparništvo te oprečne neoplatonističke misli u kontekstu antikršćanskog sentimenta (Marrou, 1970, 135-136). Aleksandrija je postala, uz afirmaciju Crkve, snažan centar kršćanske misli. Poganstvo je preživjelo, osobito među obrazovanijim slojevima, ali je prevladala koegzistencija i racionalnija atmosfera, usprkos nasilnim i fanatičnim ekscesima koji su bili obostrana značajka. ${ }^{5}$ Kršćanski i poganski učitelji i studenti u isto su vrijeme bili na istom mjestu. Poganski studenti išli su kod kršćanskih učitelja i obratno (Haas, 1997, 155). Kontakti su bili intenzivni i doveli su do zdravijeg spoja filozofskih misli, što je rezultiralo »kristijaniziranim neoplatonizmom« (Marrou, 1970, 136-140). Atena je pak otišla u drugom smjeru. Njezina je Akademija razvila »rigidni animozitet prema kršćanstvu « (Marrou, 1970, 131) te su se poganstvo i neoplatonizam počeli vezivati jedno uz drugo, i to na svim razinama, pa i onim manje racionalnim -

4 Taj članak vrlo je koristan jer se detaljno bavi upravo pitanjem filozofskih konflikata između kršćanskih i grčko-rimskih autora, stavljajući naglasak na perspektivu potonjih, te dotičući se ne samo tekstualne razine, nego i fizičkih posljedica — nasilja i progona — koje su gdjekad uzrokovali ili potaknuli upravo pripadnici intelektualne elite.

5 Christopher Haas daje iscrpnu studiju društvenog stanja u kasnoantičkoj Aleksandriji, baveći se upravo pitanjima odnosa između njezine kršćanske i poganske zajednice (uključujući i primjere nasilja), ali i razlikama unutar njih samih, primjerice razlikama između poganske populacije i inteligencije te teološkim i drugim trzavicama među kršćanima (Haas, 1997). 
raznim populističkim elementima te magijskim, okultnim i teurgijskim formama (Marrou, 1970, 136).

Uočljivi atenski smjer ipak ne skriva problem rekonstrukcije antikršćanskih misli i argumenata u neoplatonističkoj kritici. Naravno, komparativna analiza nekih općih, temeljnih karakteristika dvaju sustava dopušta neke uvjerljive pretpostavke o nepoćudnim zasadama koje su mogle smetati jednomu u odnosu na drugoga, ali ostaje činjenica da su neoplatonistički tekstovi obično izgubljeni ili fragmentarni, kao što je slučaj s Porfirijevim djelima (Emilson, 2015). Takvo stanje zahtijeva posredno čitanje izvornih misli, najčešće preko kršćanskih autora koji iste pobijaju, što je očevidan problem kojeg prati potreba da se od intelektualnih argumenata (izravno ili neizravno izvedenih iz neoplatonizma) odvoje prateći populistički antikršćanski sentimenti (Courcelle, 1970, 151).

Takav amalgam donosi Arnobije, apologet s početka 4. stoljeća, u djelu $A d$ versus gentes (ili nationes) koje služi kao odgovor antikršćanskim argumentima (kako filozofskim, tako i popularnim), upirući pritom prstom, između ostalih, u Platonove sljedbenike kao jedne od nositelja tih misli (Arnobije, 1871, 78; II.13). Štoviše, Pierre Courcelle smatra da dio argumenata, onih filozofske naravi, pripada upravo Porfiriju, jednomu od glasnijih i utjecajnijih kritičara kršćanstva (Courcelle, 1970, 154-156). Arnobije nudi kategorizaciju tih argumenata u tri osnovne premise: svijet propada i napušta vlastite prirodne zakone otkako je kršćana, nebrojene su kalvarije zadesile ljudsku rasu te je netragom nestala dotadašnja briga i zaštita nebeskih bića (Arnobije, 1871, 3-4; I.1). Pored različitih uvredljivih epiteta uperenih protiv kršćanske inteligencije, isticanja mladolikosti kršćanstva (točnije nedostatka prestiža i autoriteta drevnosti) te prizemljivanja osnovih dogmatskih zasada, nazire se intelektualnije nesuglasje — soteriološka problematika, odnosno njezin izvedbeni aspekt, te pitanje utjelovljenja logosa/ božanstva i njegove nasilne smrti, bile su osnovne jabuke razdora, uočljive u $\mathrm{Ad}$ versus gentes (Courcelle, 1970, 153-157). Pa ipak, Arnobije ističe neke sličnosti između kršćanske objave te Platonovih i platonističkih misli, ali prema Courcelleovu zaključku nema govora o pokušaju sinteze, nego je prije riječ o sarkastičnom polemičkom oružju kojim se protivnika htjelo diskreditirati njegovim vlastitim argumentima (Courcelle, 1970, 156-157).

\section{Interakcija i dijalog}

Naravno, grčka filozofska kritika kršćanstva ne počinje s neoplatonistima, odnosno ne s tradicionalno prihvaćenim „početkom“ neoplatonizma. Nešto ranije (oko 178. godine) prekinuta je dotadašnja šutnja intelektualaca. Slabo nam znani Kelso, »prvi poganski autor spisa posvećenog sustavnomu pobijanju kršćanstva « (Moreschini, 2009, 88), inicirao je sukob satiričnim napadom na kršćanstvo u danas izgubljenom spisu Alethes logos, čiju je misao opet potrebno posredno iščitavati. Upravo s njim počinje rečena filozofska kritika, a upoznajemo ju preko njegova mlađeg takmaca Origena, koji se sredinom 3. stoljeća pozabavio refutacijom u prikladno nazvanom djelu Contra Celsum (Edwards, 2014). Nastala 
opreka filozofija-kršćanstvo počinje kao obrana filozofske tradicije sa sociopolitičkim obilježjima. Kelso je prosvjedovao protiv novog, ali već primjetnog vjerovanja, u kojem vidi »negaciju svega onoga što je stoljećima bilo prisutno u grčkom geniju « (Bošnjak, 1971, 88), ali je paralelno istaknuo elemente kršćanske misli koje je prije izrekao Platon, poput nešto drugačije izrečenog ideala okretanja drugog obraza (Platon, 1970, 150-151), ali svrha je tog poteza bila »pokušaj da se dokaže kako kršćanske tvrdnje potječu od krivih tumačenja ulomaka poganskih pisaca « (Moreschini, 2009, 92). Protestirajući protiv eksluzivnosti, Kelso zauzima položaj obrane civilizacijskih stečevina — rastuće kršćanstvo, rašireno među siromašnijim i manje obrazovanim slojevima, percipirao je kao prijetnju antičkim filozofskim i vjerskim temeljima Carstva, suprotstavivši mu »vlastitu filozofiju povijesti, utemeljenu na obrani tradicionalne kulturne baštine kojoj kršćanstvo ne pripada « (Moreschini, 2009, 92), što su kršćani u to doba i praktično demonstrirali odbivši služiti u vojsci i sudjelovati u obožavanju carske osobe te u javnom i političkom životu.

A kakav stav zauzvrat zauzima kršćanstvo? Pitanje je možda pogrešno postavljeno. Pod jednom je kategorijom obuhvaćen problem koji bi zahtijevao individualne (ali ne izvankontekstualne) analize autora. Ipak, Branko Bošnjak u svojoj knjizi Grčka filozofska kritika Biblije nazire kategorijalne podtipove kršćanskog uvjerenja (u kontekstu odnosa kršćanstvo-filozofija) — Zapad izjednačuje s Tertulijanom, a Istok s Klementom Aleksandrijskim, pri čemu bi prvi trebao evocirati odbacivanje filozofije, a drugi koegzistenciju s njom (Bošnjak, 1971, 229).

Tertulijan je djelovao u prvoj polovici 3. stoljeća, dakle prije konstantinovskog obrata, apologetskom metodom braneći kršćanstvo od populističkih i često opasnih optužbi, napose onih o neprijateljstvu prema državi. O nezavidnom položaju u koji smješta antičku filozofiju svjedoči semantički paralelizam u De praescriptione haereticorum: »Što ima Atena s Jeruzalemom, što Akademija s Crkvom, što heretici s kršćanima?«(Tertulijan, 1907, 16-18; 7.9). Filozofija nije samo manjkava, niti je tek opasna zavodnica, nego je izjednačena s herezom. Iz takvog odnosa proizlazi netočno mu pripisana maksima credo quia absurdum, upravo jer nesumnjivo podređuje filozofiju vjerovanju — »nema ničega iznad vjerovanja što bismo trebali vjerovati« (Tertulijan, 1907, 18; 7.13). S druge strane, za razliku od Tertulijana zagriženog u iracionalizam, kakvog Bošnjak oslikava pod dojmom njegova sarkastičnog polemičkog stila, Claudio Moreschini nudi njegovu laskaviju verziju, onu kojoj filozofija kao takva nije strana niti nasuprot kojoj uspostavlja nepremostivu distancu. Ona može poslužiti kao priprema za vjeru, ali je uvijek manjkava jer joj nedostaje istinska objava, zbog čega ju vjera treba prevladati - to je reakcija na Kelsovu ideju kršćanstva kao plagirane filozofije, što tjera Tertulijana na dokazivanje »kako je kršćanstvo nešto više od obične filozofije« (Moreschini, 2009, 177-178).

Na drugom Bošnjakovu polu smješten je Tertulijanov suvremenik Klement Aleksandrijski, obraćenik rođen u Ateni i odgojen u grčkoj filozofskoj tradiciji, koji je postao crkveni otac i Origenov učitelj. Titulu kršćanskog filozofa zaslužio je otvorenijim, gotovo utilitarnim pristupom prema filozofiji, iskorištenoj za 
boljitak kršćanske misli, koja je dobila čvršće intelektualne temelje, koji su joj omogućili elaboraciju ranih zasada pomoću filozofskih kategorija (Swindal, s.a.). Pritom se rado pozivao na Platona, ističući paralele koje su kršćanstvu bile i ostale lako prihvatljive, poput ideje da Bog »ima u svojoj vlasti (...) početak, svršetak i sredinu svega što postoji (Platon, 1974, 159; 715e-716a). No, filozofija je u jasno podređenom položaju jer sadržava tek dio objavljene istine, ali je taj položaj bolji od onog kojeg nudi Tertulijan. Ona je također žrtva krivovjernih interpretacija i zlouporaba. Dapače, Klement smatra da kršćanstvo mora preuzeti filozofsku metodu kako bi joj se moglo kvalitetno suprotstaviti te nastoji od filozofije preuzeti »ono što je dobro i što kao takvo može poslužiti i vjerovanju (kršćanskom) kao završenoj i pravoj filozofiji« (Bošnjak, 1971, 239). Štoviše, one koji odbacuju grčku filozofiju uspoređuje s preplašenom djecom (Klement Aleksandrijski, s. a.; VI.10). Klementove utilitarne stavove naslijedio je učenik mu Origen, koji »nije vidio nikakvo proturječje između poganske filozofije i kršćanske vjere, dakako uz uvjet da se filozofiju promatra po onom što je morala biti, to jest sredstvo za produbljivanje nauka o vjeri, a ne kao samostalan nauk «(Moreschini, 2009, 124), što je svakako pomoglo infiltraciji kršćanstva u intelektualne krugove.

Unatoč primjeru Klementa, Bošnjak barata ponajviše antitezama, uspostavljajući gotovo biti-ili-ne-biti narativ u kojem nema spomena o izrazito zanimljivoj kasnoantičkoj ličnosti čija priča uspostavlja novu perspektivu. U plodnijoj intelektualnoj atmosferi pružene slike Aleksandrije, izdvaja se učenik spomenute Hipatije, polaznik „poganske“ filozofske škole koji je postao, doduše nevoljko i zakratko, kršćanski biskup grada Ptolemaisa u Cirenaici (Marrou, 1970, 127 128). To je Sinezije, prije retoričar nego filozof, koji je živio na prijelazu iz 4. u 5. stoljeće i koji je bio visoko obrazovan u autentičnoj filozofskoj tradiciji, te o čijem se doprinosu mogu naći oprečna mišljenja. Marrou, primjerice, u Sinezijevom djelu ne otkriva zavidnu inovativnost (Marrou, 1970, 130), a Moreschini u njegovu baratanju neoplatonizmom vidi svježu i originalnu preradu (Moreschini, 2009, 593). Zanimljivost njegove osobe proizlazi iz kompleksne naravi njegova obraćenja. Primjer je sukoba neoplatonističke i kršćanske misli utjelovljene u jednom čovjeku (Marrou, 1970, 128-131). Sinezije je nesumnjivo bio upoznat s kršćanstvom, ali pitanje je li već bio kršćanin ili ne kada je bez entuzijazma prihvatio biskupski položaj, bilo je ono oko kojeg su ležala polomljena koplja. Trenutačni konsenzus kaže da jest, no osim osnovnog prihvaćanja kršćanske vjere, Sinezije je ispunjavao i druge kriterije za položaj biskupa koje je tadašnji kontekst zahtijevao - govorničku vještinu, administrativne sposobnosti i građansku istančanost, zasluženu ponajviše u borbama protiv neprijatelja njegova grada (Pavić i Tenšek, 1993, 171). U prilog konsenzusu također svjedoče i njegova pisma, koja ne otkrivaju odbojnost prema samomu kršćanstvu, nego prije prema biskupskoj službi koja bi, u interakciji s popularnim, priječila djelatnost u kojoj je kao dio intelektualne elite uživao, a to je filozofija (Sinezije, 2015).

Sinezije je iznimna pojava svoje vrste — nema smisla poricati — ali mogao bi poslužiti kao indikator stajališta obrazovanih o odnosu kršćanstva i filozofije, barem što se tiče aleksandrijskog kruga. Stanoviti otpor prema kršćanstvu koji 
se uočava kod intelektualne elite proizlazi iz društveno-vjerskih razloga, ali ne iz ovakvog ili onakvog poganstva, nego iz onog što H. I. Marrou naziva religijom Kulture (Marrou, 1970, 143). To bi bio klasičan ideal paideia, koji predstavlja teško dohvatljive i strogo čuvane vještine koje su pretpostavljale određenu socijalnu distancu i zatvorenost (Brown, 1992, 39). Magnet za inicirane u rečeni ideal nije dakle tobožnje poganstvo, nego su to kultura i filozofija, nedostatak kojih je bitan uzrok tekstualnih sukoba, koji opet, čini se, nisu vjerske, nego kulturološke naravi. Drugim riječima, upravo je kultura, a ne vjera, ključna pri uspostavi društvenih granica (Haas, 1997, 156). Stoga, oponenti pritom mogu biti i kršćani i pogani. Vulgarna uvjerenja kršćanske svjetine, toliko mrska Sineziju, potencijalne su pogibelji za kulturu, jednako kao loša filozofija poganskih mislilaca ili korumpirani neoplatonizam okaljan praznovjerjem i teurgijom, kojeg demonstrira atenski smjer pod utjecajem Jamblihova učenja, distanciranog od originalne Plotinove misli (Moore, s.a.). U tom duhu Hipatija je mučenica, ali ne može pripadati poganstvu, nego upravo filozofiji, kao mučenica obrazovane kasnoantičke elite i žrtva nasilja koje je pobjeglo iz svojeg tekstualnog okrilja.

Izrečeno upućuje na drugačiji izvor filozofske kritike kršćanstva od pretpostavljenog. To nije glas nekakvog poganstva, nego obrazovanog čovjeka antičkog svijeta čiji intelektualni ponos s visoka gleda, ne na kršćanstvo, nego na ono što u vlastitoj svijesti percipira kao popularno ili vulgarno, neovisno kojoj kategoriji pripada. Paralelno s time, odbojnost prema vulgarizaciji javlja se i kod kršćanskih filozofa, primjerice Klementa koji se suprotstavlja simplifikacijama kršćanskih masa nezainteresiranih za dublji smisao vlastite vjere (Moreschini, 2009, 107).

\section{Zaključak}

Dakle, kako izgleda tekstualni trokut kršćana, pogana i neoplatonista? Malobrojnost primjera dopušta, za početak, barem ovo: koje god se kategorije uzmu, odnos nije jednoznačan i ne počiva isključivo na antitezi. Naprotiv, kompleksne je naravi, dodatno otežane kategorijalnom nepreciznošću, stoga je i nesvodiv na jednu paradigmu ili objasnidbeni model. Stoga, nužno je posegnuti za pluralom — odnosima, te suziti terminološki horizont s ciljem preciznijih analiza.

Ako idilična karakterizacija nije nužno na mjestu, nije ni njezin antipod poganstvo može biti dio uskog kruga obrazovanih ljudi, a i ne mora. Njegove veze s neoplatonizmom mogu biti bliže ili dalje ili pak potpuno marginalne, ovisno o strani Mediterana koja se uzima u obzir ili o pojedinačnim autorima čiji su nam glasovi ostali više ili manje očuvani. Kršćanski su autori gdjekad s uvredljivim namjerama izjednačavali (neo)platonizam i poganstvo, ali među njima tek u specifičnim slučajevima može stajati stidljivi znak jednakosti, i to onaj koji će s lakoćom ustupiti mjesto stvarnomu stanju te priznati kompleksnost međuodnosa i, osim toga, činjenicu da je patristička filozofija ranog kršćanstva ne samo polemizirala s neoplatonizmom, nego je i bila pod njegovim izrazitim utjecajem. K tomu, slučaj Sinezija jasno svjedoči da je ta veza mogla biti i mnogo intimnija. To je značenje neoplatonizma kao nezavisne filozofije bez a priori postavljenih sen- 
timenata prema kršćanstvu jer raspon obuhvaća emocije filozofa od animoziteta, preko ravnodušnosti do kakvih-takvih simpatija.

Zauzvrat, kršćanstvo ne ostaje dužno. Kao religio illicita obično je reagiralo na kritike apologijom, ali su jasni različiti odnosi prema neoplatonizmu i filozofiji kao takvoj. Kasnije, nakon sudbonosne vladavine Konstantina Velikog, prvog kršćanskog cara, apologija je opstala, ali zapravo se „stolovi okrenuše“ jer grčka je filozofija svoje odradila. Poslužila je kao plodno tlo na kojem je teologija ispunila svoj puni potencijal i zauzela mjesto svoje prethodnice, koja je srednjovjekovlje preživjela kao ancilla theologiae. Ako tekstualni sukob nekad i nije bio za one slabijeg želuca, ipak je uspostavio koristan dijalog između kršćanstva i neoplatonizma, koji se pokazao kao filozofski izazov za mladu vjeru i koji je upravo zahvaljujući povremenomu vehementnomu prepucavanju utjecao na razvoj teologije, sada obogaćene filozofskim kategorijama i metodama, te olakšao put kršćanstvu do obrazovanih slojeva.

\section{Literatura:}

Arnobije (1871). Adversus gentes. U: Hamilton Bryce i Hugh Cambell (ur.), The Seven Books of Arnobius Adversus Gentes. Edinburgh: T \& T Clark. URL: https://archive. org/stream/thesevenbooksofa00arnouoft\#page/n29/mode/2up (10.12.2017.)

Aurelije Augustin (1995). O državi Božjoj: De civitate Dei: Svezak prvi. Preveo Tomislav Ladan. Zagreb: Kršćanska sadašnjost.

Bošnjak, Branko (1971). Grčka filozofska kritika Biblije: Kelsos contra apologeticos. Zagreb: Naprijed.

Brown, Peter (1992). Power and Persuasion in Late Antiquity: Towards a Christian Empire. Madison, WI: The University of Wisconsin Press.

Cameron, Alan (2011). The Last Pagans of Rome. Oxford — New York: Oxford University Press.

Courcelle, Pierre (1970). Anti-Christian Arguments and Christian Platonism: from Arnobius to St. Ambrose. U: Arnaldo Momigliano (ur.), The Conflict between Paganism and Christianity in the fourth century (str. 151-192). Oxford: Clarendon Press.

Edwards, Mark J. (2014). Origen. U: Stanford Encyclopedia of Philosophy. URL: http:// plato.stanford.edu/entries/origen/\#Oth (17.7.2016.)

Emilson, Eyjólfur (2005). Porphyry. U: Stanford Encyclopedia of Philosophy. URL: http:// plato.stanford.edu/entries/porphyry/ (11.7.2016.)

Gerson, Lloyd (2003). Plotinus. U: Stanford Encyclopedia of Philosophy. http://plato.stanford.edu/entries/plotinus/ (5.7.2016.)

Haas, Christopher (1997). Alexandria in Late Antiquity: Topography and Social Conflict. Baltimore - London: The Johns Hopkins University Press.

Ignacije Antiohijski (2010). Rimljanima. U: Ivan Bodrožić (ur.), Apostolski oci I. Ignacije Antiohijski: Pisma; Polikarp: Poslanica Filipljanima; Polikarpovo mučeništvo. Preveo Branko Jozić. Split: Verbum.

Jenkins, Philip (2001). Hidden Gospels: How the Search for Jesus Lost Its Way. New York: Oxford University Press.

Jones, Christopher P. (2014). Between Pagan and Christian. London - Cambridge, MA: Harvard University Press. 
Jürgasch, Thomas (2016). Christians and the Invention of Paganism in the Late Roman Empire. U: Michele Renee Salzman, Marianne Sághy, Rita Lizzi Testa (ur.), Pagans and Christians in Late Antique Rome: Conflict, Competition, and Coexistence in the Fourth Century (str. 115-138). Cambridge: University Press.

King, Karen L. (2008). Which Early Christianity? U: Susan Ashbrook Harvey i David G. Hunter (ur.), The Oxford Handbook of Early Christian Studies. Oxford - New York: Oxford University Press.

Klement Aleksandrijski (s. a.). The Stromata, or Miscellanies. U: Early Christian Writings. URL: http://www.earlychristianwritings.com/text/clement-stromata-book6.html (10.12.2017.)

Marrou, Henri Irénée (1970). Synesius of Cyrene and Alexandrian Neoplatonism. U: Arnaldo Momigliano (ur.), The Conflict between Paganism and Christianity in the fourth century (str. 126-150). Oxford: Clarendon Press.

Medved, Marko; Siljeg, Franjo (2011). O vjerskoj toleranciji u prvim stoljećima kršćanstva. Riječki teološki časopis, 38, 403-436.

Moreschini, Claudio (2009). Povijest patrističke filozofije. Preveo Slavko Antunović. Zagreb: Kršćanska sadašnjost.

Moore, Edward (s.a.). Neo-Platonism. U: Internet Encyclopedia of Philosophy. URL: http://www.iep.utm.edu/neoplato/ (24.7.2016.)

O'Donnell, James J. (2015). Pagans: The End of Traditional Religion and the Rise of Christianity. New York: HarperCollins Publishers.

Pavić, Juraj; Tenšek, Tomislav Zdenko (1993). Patrologija. Zagreb: Kršćanska sadašnjost. Platon (1974). Zakoni. Preveo Veljko Gortan. Zagreb: Naprijed.

Platon (1970). Kriton. U: Dijalozi. Beograd: Kultura.

Sághy, Marianne; Schoolman, Edward M. (2017). Introduction. U: Marianne Sághy i Edward M. Schoolman (ur.), Pagans and Christians in the Late Roman Empire: New Evidence, New Approaches (4th-8th centuries) (str. 1-10). Budimpešta: CEU Press.

Simmons, Michael Bland (2002). Graeco-Roman Philosophical Opposition. U: Philip F. Esler (ur.), The Early Christian World: Volume I. (str. 840-868). New York — London: Routledge.

Sinezije (2015). Letter 105. U: Livius.org: Articles on ancient history. URL: http://www. livius.org/sources/content/synesius/synesius-letter-105/ (8.12.2017.)

Swindal, James (s. a.). Faith and Reason. U: Internet Encyclopedia of Philosophy. URL: http://www.iep.utm.edu/faith-re/ (19.7.2016.)

Tertulijan (1907). De praescriptione haereticorum. U: Hippolyte Hemmer i Paul Lejay (ur.), Tertullien De praescriptione haereticorum: Texte latin, traduction française, introduction et index par Pierre de Labriolle. Pariz: Librairie Alphonse de Picard et fils. URL: https://archive.org/details/depraescription00tert (12.9.2017.)

Wildberg, Christian (2016). Neoplatonism. U: Stanford Encyclopedia of Philosophy. URL: http://plato.stanford.edu/entries/neoplatonism/\#HisOriAnt (2.7.2016.) 
Christians, Pagans and Neoplatonists - The Problem of Relations in Late Antiquity

Tomislav Čanković*

\section{Summary}

This article reevaluates the popular perception of the struggle between a dying paganism and a triumphant Christianity in late antiquity and focuses on the textual ,battle of the minds" between some of the most prominent figures of Neoplatonic philosophy and Christian thought. After clarifying some terminology issues and addressing the place of pagans in the society of that time, the article examines the differences amongst Neoplatonic philosophers in regard to Christianity and amongst Christian authors in regard to Neoplatonism and philosophy in general, thus avoiding the simple division between the two. Neoplatonists are represented by the symbolic use of Athens and Alexandria, which indicate various dispositions and attitudes towards Christianity. On the other hand, Christians are presented through the different levels of their (dis)agreement with Neoplatonism and stances ranging from defensive through tolerant to aggressive. The complexity of such relations is further revealed by introducing Synesius of Cyrene, a student of Neoplatonism from Alexandria who was elected bishop of Ptolemais in North Africa.

Key words: Christianity, Neoplatonism, paganism, Synesius of Cyrene 